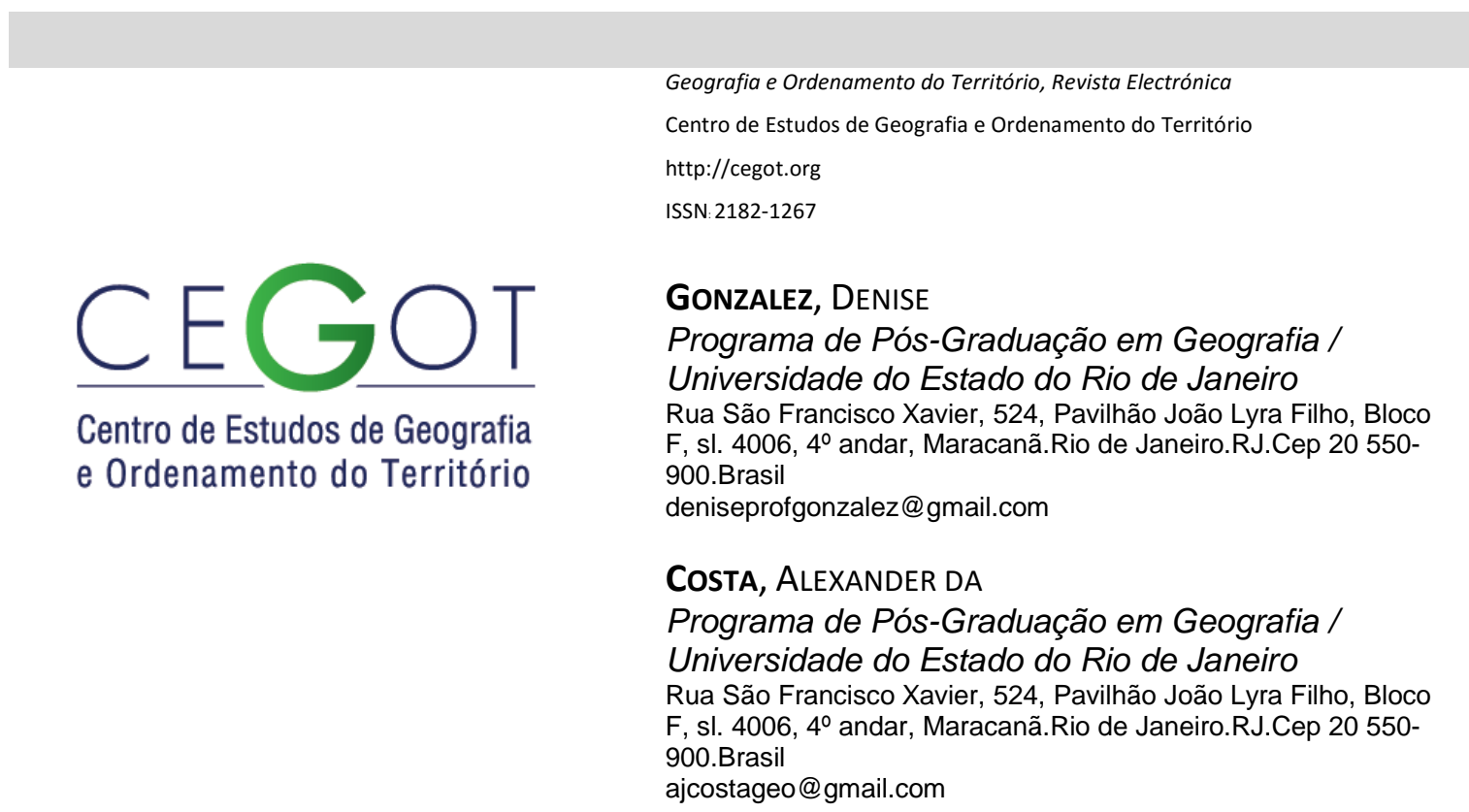

\title{
Análise da percepção de risco e vulnerabilidade a partir dos alunos do ensino médio na vivência de Nova Friburgo RJ após desastre natural de 2011
}

\begin{abstract}
Risk perception and vulnerability analysis from high school students in Nova Friburgo RJ experience after natural disaster 2011
\end{abstract}

Referência: Gonzalez, Denise; Costa, Alexander da (2016). Análise da percepção de risco e vulnerabilidade a partir dos alunos do ensino médio na vivência de Nova Friburgo RJ após desastre natural de 2011. Revista de Geografia e Ordenamento do Território (GOT), n.o 9 (junho). Centro de Estudos de Geografia e Ordenamento do Território, p. 187-211, dx.doi.org/10.17127/got/2016.9.009

\section{RESUMO}

A precipitação intensa num intervalo de poucas horas, causou uma série de deslizamentos de encostas e enchentes e/ou inundações de rios na Região Serrana do Estado do Rio de Janeiro, Brasil, especialmente no município de Nova Friburgo no mês de janeiro de 2011. Baseada na vivência dos alunos do 1 을 ano do Ensino Médio de dois colégios da rede estadual de ensino, esta pesquisa se utilizou do fato desta região ter sofrido este evento extremo. Observou-se a percepção de risco dos alunos através do que viveram e com os conteúdos da geografia Com o aplicativo Google Earth,foi elaborado o mapa de área de risco pelos mesmos, havendo uma comparação entre os resultados encontrados nas duas escolas, além de confrontá-los com dados da prefeitura sobre o assunto. Além disso, houve a análise da vulnerabilidade da população a partir de mapas temáticos com base no censo do IBGE(2010).

Palavras-chave: Desastre Natural, Percepção de risco, Ensino de Geografia, Área de risco; Vulnerabilidade 


\begin{abstract}
Intense rainfall in the range of a few hours, caused a number of landslides slopes and/or flood rivers in the mountainous region of the State of Rio de Janeiro, Brazil, especially in the Nova Friburgo municipality in January 2011. Based on the experience of high school students in the 1st year of two colleges of the state schools in this municipality, this research will use the fact that this region has suffered this extreme event. The students' perception of risk was analyzed through their own experience and,using the geography contents for their series and Google Earth applicative, they elaborated a risk area map. Afterwardsthe results found in both schools were compared and confronted withthe city data on the subject. Furthermore, analysis of the population vulnerability was done from thematic maps based on IBGE census (2010).
\end{abstract}

Keywords: Natural Disaster, Risk perception, Geography Learning, Risk area, Vulnerability.

\title{
1. Introdução
}

Eventos extremos de natureza climática e geológica sempre ocorreram em diferentes partes do planeta. No entanto, as condições de fragilidade ambiental e/ou socioeconômica expõem determinadas populações a um risco maior. Em muitas regiões na maioria das vezes, onde ocorre o predomínio da população de baixa e baixíssima renda e com falta de informações a respeito de risco ambiental, o desastre se repete provocando várias mortes. Esta situação de extremos de natureza meteorológica e geológica foi verificada também na Região Serrana do Estado do Rio de Janeiro, especialmente em Nova Friburgo, no mês de janeiro de 2011. A ocorrência de precipitação intensa num intervalo de poucas horas causou uma série de deslizamentos de encostas e enchentes de rios, atingindo áreas rurais e urbanas de municípios serranos.

Nesta "Tragédia", como popularmente se referem os habitantes friburguenses àenchente e aos deslizamentos com grande número de mortes em janeiro de 2011, os locais afetados não foram somente aqueles considerados como principais áreas de risco, como beiras dos rios e áreas desmatadas da periferia de baixa renda, mas também em áreas com cobertura vegetal, urbanas e rurais devido à intensidade de precipitação e saturação dos solos. Junto a isto, as condições físicas de vertentes íngremes, solos rasos e vales estreitos configuram uma suscetibilidade maior aos processos geomorfológicos de movimentos de massa e 
enxurradas. As atividades de uso e ocupação da terra podem, ou não, aumentar a fragilidade ambiental da região. No caso de Nova Friburgo, não houve distinção de classes sociais onde toda a população então se viu envolvida direta ou indiretamente, pois durante uma semana grande parte do município ficou sem comunicação, sem condições de acesso e mesmo com problemas de abastecimento básico visto que o caos foi gerado.

A escola, como parte indispensável na formação do indivíduo/cidadão pode incorporar ao seu currículo os avanços do conhecimento e das técnicas do setor acadêmico com as devidas adaptações.

Este artigo é uma parte de uma pesquisa baseado na vivência dos alunos do 10 ano do Ensino Médio de dois colégios da rede estadual do município de Nova Friburgo-RJ, se utilizando do fato deste município ter sofrido um grande desastre ambiental. Uma escola analisada se localiza no distrito sede, ou seja, em área mais urbana, e a outra se localiza no 8 o distrito (Mury), com características mais rurais, onde o uso e cobertura do solo que predomina é de cobertura vegetal de floresta.

No referido ano, os principais conteúdos ministrados referem-se à Geografia Física, como fatores e elementos geológicos, geomorfológicos, bacias hidrográficas, clima, vegetação, impactos ambientais, além de noções importantes de cartografia. Pretende-se articular tais conteúdos com atividades práticas e participativas ambientais para viabilizar a discussão de risco ambiental e promover uma maior percepção de risco dos estudantes, a fim de que os mesmos façam uma análise ambiental para um melhor ordenamento e planejamento territorial inicialmente através da elaboração de um mapa de área de risco.

As atividades práticas envolveram o mapeamento de possíveis áreas de risco natural, o uso das geotecnologias como apoio didático objetivando fazer a interação entre o real e o abstrato, possibilitando com isso o aumento da sua percepção de risco e, ao mesmo tempo tornando as aulas mais motivadoras. Houve a possibilidade de uma alfabetização cartográfica e Educação Ambiental. Ressalta-se que esta concepção está dentro dos Parâmetros Curriculares Nacionais (PCNs) elaborados pelo MEC (Ministério de Educação e Cultura) para o programa de Geografia. Ademais, tais procedimentos vão ao encontro do EIRD (Estratégias internacionais de Redução de Desastres) da ONU (Organização das Nações 
Unidas) e firmado em 2005 o Marco de Ação de $\mathrm{Hyogo}^{1}$, que até 2015 pretende promover espaço a mais o aumento de resiliência ${ }^{2}$ das nações e comunidades frente aos desastres. A partir do estabelecimento do Marco de Hyogo várias ações para a redução de desastres foram estabelecidas ao redor do mundo. Uma delas é desenvolver programas de risco em sala de aula, com a finalidade de preparar os estudantes a enfrentar os eventos de desastres, reduzindo assim os riscos e o número de mortes nesta parcela da população tão vulnerável a eles. (SAUSEN, 2013)

A defesa civil municipal de Nova Friburgo vem desenvolvendo na fase de prevenção alguns trabalhos efetivos voltados para as escolas como palestras sobre desastres naturais e percepção permitindo que os alunos desenvolvam a percepção dos riscos aos desastres. Porém, são muitas escolas para que se promova uma cultura preventiva no país. Esta, ao ser implantado, poderá ser transmitir de forma adequada os conceitos e práticas da gestão de risco a desastres aos alunos, os quais poderão ser multiplicadores em seus lares e comunidades, transmitindo quais são as medidas possíveis frentes aos fenômenos naturais desencadeadores de desastres bem como aos desastres de natureza antrópica.

Considerando ainda que o processo educativo deva contribuir para a superação do atual quadro de desinformação de grande parte da população acercadas ações preventivas, é necessário que a escola, desperte a percepção de risco sobre os desastres que as mudanças climáticas impõem ao mundo contemporâneo (CATANHO, 2012).

O Objetivo Geral é analisar a percepção de risco e vulnerabilidade da população dos alunos do 10 ano do Ensino Médio de duas escolas da rede estadual de ensino na vivência de Nova Friburgo-RJ após o desastre natural de janeiro de 2011.

Temos como primeiro objetivo específico analisar a percepção de risco dos alunos do 10 ano do Ensino Médio na vivência de Nova Friburgo-RJ através dos conteúdos de Geografia Física e introdução das geotecnologias através da elaboração do mapa de área de risco com o uso do aplicativo gratuito via internet Google Earth.Como segundo objetivo específico,

\footnotetext{
${ }^{1}$ Documento firmado por 168 países e três organizações supragovernamentais no ano de 2005 com o objetivo de aumentar a resistência das nações e comunidades frente aos desastres.(NAÇÕES UNIDAS, 2009)

2a capacidade de uma comunidade exposta ao perigo e ao risco em resistir, absorver, adaptar-se e recuperarse dos efeitos de um evento, em tempo adequado e de forma eficaz, o que inclui a preservação e a restauração de suas estruturas e funções básicas (NAÇÕES UNIDAS, 2009).
} 
pretendemos analisar a vulnerabilidade da população residente em pontos de risco a escorregamentos e inundações percebidos pelos alunos do 1 으 ano do Ensino Médio,comparando-os entre as escolas e com os dados oficiais.

\section{Base Conceitual}

\subsection{Desastres Naturais}

Os desastres naturais podem ser provocados por diversos fenômenos, tais como, inundações, escorregamentos, erosão, terremotos, tornados, furacões, tempestades, estiagem, entre outros. São aqueles causados por fenômenos e desequilíbrios da natureza que atuam independentemente da ação humana. Em geral, considera-se como desastre natural todo aquele que tem como gênese um fenômeno natural de grande intensidade, agravado ou não pela atividade humana (TOMINAGA, 2009).

Além da intensidade dos fenômenos naturais, o acelerado processo de urbanização verificado nas últimas décadas, em várias partes do mundo, inclusive no Brasil, levou ao crescimento das cidades, muitas vezes em áreas impróprias à ocupação, aumentando as situações de perigo e de risco a desastres naturais (TOMINAGA, 2009).

Para a Defesa Civil Nacional, desastre é tratado como sendo:

... resultado de eventos adversos, naturais ou provocados pelo homem, sobre um ecossistema (vulnerável), causando danos humanos, materiais e/ou ambientais e consequentes prejuízos econômicos e sociais. A intensidade de um desastre depende da interação entre a magnitude do evento adverso e o grau de vulnerabilidade do sistema receptor afetado. (CASTRO,1998)

\subsection{Riscos}

O conceito de risco tem sido utilizado em diversas ciências e ramos do conhecimento que tratam assuntos ambientais de forma diferente. Vários termos são utilizados para riscos como acidentes, áleas, desastres, hazards entre outros. Álea, segundo Veyret (2007), corresponde

... a um acontecimento possível, decorrente de um processo natural, tecnológico, social, econômico, havendo possibilidade de realização. Se vários acontecimentos são possíveis fala-se de um conjunto de áleas. Em inglês, o termo equivalente é hazard.(VEYRET,2007) 
Perigo e risco são conceitos diferentes e ao mesmo tempo complementares. Segundo os conceitos propostos pela Organização das Nações Unidas (ONU), perigo é considerado como uma circunstância que prenuncia um mal para alguém ou alguma coisa, portanto pode causar dano, perda ou prejuízo ambiental, humano, material ou financeiro; e riscocomo sendo a probabilidade (ou freqüência) esperada de ocorrência dos danos, perdas ou prejuízo conseqüentes da consumação do perigo. (NAÇÕES UNIDAS,2004).

O risco é a probabilidade mensurável de um perigo transformar-se em desastre. Veyret (2007) descreve que "não há risco sem uma população ou indivíduo que o perceba e que poderia sofrer seus efeitos".

Para a Defesa Civil podemos dizer que risco é:

Medida de danos ou prejuízos potenciais, expressa em termos de probabilidade estatística de ocorrência e de intensidade ou grandeza das conseqüências previsíveis ou relação existente entre a probabilidade de que uma ameaça de evento adverso ou determinado acidente se concretize, com o grau de vulnerabilidade do sistema receptor aos seus efeitos (BRASIL, p. 8, 2007).

Segundo Marcelino (2008, p.24) os desastres estão interligados as fragilidades ambientais e as vulnerabilidades sociais da área que propiciam a transformação em desastres como exposto a seguir:

... a quantidade dos desastres também pode estar vinculada aos elementos sociais expostos, ou seja, à fragilidade do ambiente socialmente construído (vulnerabilidade) (...)aumentando a frequência do perigo e a intensidade da vulnerabilidade, aumentará consequentemente o risco de um perigo transformar-se em desastre.(MARCELINO, 2008, p.24)

\subsection{Vulnerabilidade}

A vulnerabilidade é o grau de perda para um dado elemento, grupo ou comunidade dentro de uma determinada área passível de ser afetada por um fenômeno ou processo. Esta é determinada por fatores ou processos físicos, sociais, econômicos e ambientais que aumentam a suscetibilidade aos impactos ambientais Esta última por sua vez, indica a potencialidade de ocorrência de processos naturais e induzidos em uma dada área, expressando-se segundo classes de probabilidade de ocorrência. (SAUSEN, 2015) 
Os desastres naturais podem ocorrer em qualquer continente, região, ou país do mundo. Algumas regiões são mais afetadas devido à magnitude e à frequência dos fenômenos e à vulnerabilidade do sistema social. Alguns grupos populacionais também podem ser mais vulneráveis que outros, como são o caso de crianças e idosos (SAUSEN, 2015).

Hogan et al. (1992) concentrou esforços para caracterizar a população vulnerável a riscos a enchentes e deslizamentos. Assim, testou a possibilidade de uso de dados censitários georreferenciados (ao nível do setor censitário) para caracterizar riscos ambientais em uma cidade e as populações vulneráveis sujeitas a esses riscos. Nesta proposta, como fez Torres, 1997 apud Hogan et al.(1992), é demonstrar a relação existente entre o risco ambiental e a condição social.

Podemos definir setor censitário como uma ferramenta operacional do IBGE-Instituto Brasileiro de Geografia e Estatísitica (um setor é a área que o recenceador pode cobrir durante o período do Censo, geralmente composto por 200 a 300 domicílios) e as mudanças nos padrões de densidade dentro da malha urbana forçam a redefinição dos limites dos setores (HOGAN et al.,1992).

\subsection{Percepção de Risco}

Marandola Jr e Modesto (2012) defendem que se necessita, primeiro, compreender a percepção das pessoas sobre os perigos que aparecem em sua experiência para, somente depois, pensar a dimensão dos riscos envolvidos.

A percepção é intuitiva, imediata, e é por isso que, com relação à maioria dos perigos, as pessoas não passam da sua percepção, pois não chegam a refletir ou elaborá-los enquanto tal. Os perigos são constituintes da história de vida das pessoas e da própria forma como elas se colocam nas cidades, como elas constroem suas identidades, mas nem sempre se tornam conscientes. (MARANDOLA JR; MODESTO, 2012.p. 13)

Os perigos são tangíveis e sua percepção é parte integrante do próprio fenômeno. É ela que nos leva a uma elaboração cognitiva para o entendimento dos riscos (Marandola Jr; Modesto, 2012). Analisar a percepção de risco, ainda, pressupõe considerar juízos, memória, emoção e motivação das pessoas que fazem parte do contexto analisado.

Na visão de TUAN (1983) a percepção ambiental é: 
a resposta dos sentidos do indivíduo aos estímulos externos emitidos pelo espaço que o circunda. Podemos interpretar que esta resposta captura o indivíduo da condição passiva de mero observador do meio ambiente e o transporta ao nível da ação, quando este indivíduo não só utiliza a visão como também a cognição...

Veyret (2007) afirma que a análise histórica permite compreender melhor as percepções do risco, os diversos modos de aceitação pelos diferentes atores e os mecanismos da "memória do risco e das catástrofes", uma vez que a memória coletiva não é neutra. Apontam a importância de analisar como essas memórias se perpetuam, são esquecidas ou funcionam como acontecimentos aglutinadores, através da formação de uma espécie de identidade social.

A possibilidade do desenvolvimento da percepção do risco implementada junto à matriz curricular das instituições de ensino pode criar uma nova cultura de risco para que os jovens adquiram uma percepção de risco, e num futuro próximo, a sociedade poderá torna-se resiliente frente às mudanças climáticas associadas às intervenções antrópicas e assim, possam com os conhecimentos adquiridos, mitigar (suavizar) os danos e prejuízos oriundos de fenômenos físicos naturais. Tais procedimentos estão na Política Nacional da Defesa Civil (Brasil, 2012) mas que no momento somente o estado do Ceará introduziu na grade curricular, mas ainda não estão sendo aplicadas adequadamente nas escolas (CATANHO 2012)

Neste sentido, a percepção de risco como categoria de análise busca preencher lacunas encontradas em trabalhos e pesquisas de campo acerca do descompasso entre as políticas públicas recém efetivadas (através da Lei 12.608/2012) e seu rebate na realidade dos moradores destas áreas. Mostra-se necessário ampliar as investigações que considerem a visão e comportamento dos moradores, das organizações comunitárias e mesmo dos jovens através da educação nas escolas como meio de redução dos desastres relacionados às chuvas intensas.

\section{5. Área de risco}

A área de risco é então para a Defesa Civil como "área onde existe a possibilidade de ocorrência de eventos adversos" (Castro, 1998) e também para o Ministério das Cidades: 
... área passível de ser atingida por fenômenos ou processos naturais e/ou induzidos que causem efeito adverso. As pessoas que habitam essas áreas estão sujeitas a danos a integridade física, perdas materiais e patrimoniais. Normalmente, no contexto das cidades brasileiras, essas áreas correspondem a núcleos habitacionais de baixa renda (assentamentos precários). (BRASIL.IPT, 2007).

As áreas de risco a enchentes e inundações são:

enchente e inundação são os terrenos marginais e cursos d'água ocupados por núcleos habitacionais precários sujeitos ao impacto direto desses fenômenos). "As pessoas que habitam essas áreas estão sujeitas a danos a integridade física, perdas materiais e patrimoniais. (BRASIL. IPT,2007)

O zoneamento de risco geológico pelos órgãos públicos se inicia com a pré setorização da área, utilizando-se a percepção ou experiência do profissional nos trabalhos de mapeamento juntamente com os parâmetros básicos a serem observados como a Declividade/inclinação ${ }^{3}$; Tipologia dos processos;Posição da ocupação em relação à encosta; Qualidade da ocupação (vulnerabilidade). (BRASIL. IPT, 2007). O mapeamento de risco é importante para o planejamento territorial onde o Plano diretor municipal (Lei 10257/2001) tem como prerrogativa este mapeamento. A unidade de planejamento territorial é a bacia hidrográfica(Coelho Neto, 1995). Assim, proteger as APPs como as margens dos rios( Brasil, 1965) deve ser transferido para o conhecimento escolar e na disciplina Geografia tem como um dos temas de estudo para o 1ㅇano do Ensino Médio o tema bacias hidrográficas.

\subsection{Desastres Naturais na região sudeste do Brasil}

Os movimentos de massa (quedas, tombamentos e rolamentos de rochas, deslizamentos ou escorregamentos e corrida de massa) afetam principalmente as regiões Sul, Sudeste e Nordeste, com maior incidência no verão. O escorregamento ou deslizamento translacional ou planar é o tipo de movimento de massa que mais ocorre na região serrana do estado do Rio de Janeiro.

\footnotetext{
${ }^{3} \mathrm{~A}$ declividade/inclinação pode variar de acordo com o tipo de solo, rocha, relevo, ou de acordo com as intervenções antrópicas, como cortes e aterros. Existem valores de referencia para este parâmetro, acima dos quais a deflagração do processo de deslizamento e iminente. Como referencias temos:".(BRASIL. IPT, 2007) _ 170 (30\%) Lei Lehman (Lei Federal 6766/79), que determina que áreas com declividades acima de 30\% devem ter sua ocupação condicionada a não existência de riscos (verificado por laudo geológico-geotécnico); _ 20은 e a declividade onde ja se iniciam os deslizamentos na Serra do Mar no litoral paulista.
} 
A região Sudeste, além de apresentar uma população total maior do que a demais região registra o maior número de ocorrências de inundações bruscas e movimentos de massa, os dois tipos de desastre responsáveis pelo maior número de óbitos nesta região e no país.

A inundação também segundo o Ministério das Cidades (BRASIL, IPT,2007)representa o transbordamento das águas de um curso d'água, atingindo a planície de inundação OU área de várzea. Já as enchentes ou cheias são definidas pela elevação do nível d'água no canal de drenagem devido ao aumento da vazão, atingindo a cota máxima do canal, porém, sem extravasar.

\subsection{As geotecnologias para o planejamento ambiental}

Os recentes avanços tecnológicos vividos desde a década de 1980 até os dias de hoje, trouxeram inovações não somente para os meios de informação e comunicação, como também para a Geografia e Cartografia. Dentre estas mudanças, podemos apontar o desenvolvimento das Geotecnologias, que são as tecnologias envolvidas com a aquisição de dados espaciais, processamento e manipulação destes dados, armazenamento e apresentação de informações espaciais

O Sensoriamento Remoto e Sistema de Informação Geográfica são conceitos bem distintos. O primeiro é a ciência de obtenção de dados da superfície terrestre através de imagens obtidas por sensores aerotransportados ou a bordo de satélites orbitais, enquanto que o segundo é utilizado para armazenar, gerenciar e manipular estes dados, a fim de revelar novas informações.

Atualmente a internet tornou possível o alcance desta tecnologia a um público bastante amplo, com programas de SIG livres e algumas ferramentas colaborativas. Existem SIGs livres e diversos portais na internet que disponibilizam imagens de satélite, bases cartográficas e outros dados, o que possibilita de uma maneira cada vez mais abrangente, reunir, processar e entender melhor as informações ambientais de forma integrada, os quais podem ser usados no planejamento e execução de estudos e atividades fundamentais à gestão ambiental. 
O uso de imagens de satélite, por suas características multiespaciais e multitemporais, pode contribuir, para a expansão dos conhecimentos cartográficos no ensino em diferentes áreas do conhecimento, e em particular na geografia, servindo ainda, como "ferramentamotivacional" no processo de ensino-aprendizagem. Em consonância com os Parâmetros Curriculares Nacionais (Brasil,1998), que apontam para a necessidade de utilização de diferentes fontes de informação e recursos tecnológicos na aquisição e construção do conhecimento, a utilização e difusão dessas novas tecnologias na educação básica, pode contribuir para a melhoria na qualidade doensino e, conseqüentemente, para a formação de uma sociedade mais responsável na utilização sustentável dos recursos naturais do planeta (CARVALHO, 2006).

Assim, o presente trabalho se baseia na abordagem da construção de um mapa de área de risco pelos alunos através do Google Earth visto que este é um aplicativo gratuito via internet que surgiu a partir de 2005 onde também pela mesma forma o aluno consegue informações para manuseio através também do aplicativo Youtube.

O Google Earth permite então mover a imagem, utilizar ferramentas para aumentar ou diminuir a escala de visualização (através do zoom) do fenômeno, traçar caminhos e calcular distâncias entre os lugares podendo fazer o perfil topográfico do caminho traçado. Através da ferramenta streetviewpode-se "caminhar" por locais conhecidos ou desconhecidos como se tivesse no lugar (em outra perspectiva), gravar vídeos e identificar transformações nas paisagens nos últimos anos. Tais procedimentos permitem que uma pessoa com pouco conhecimento cartográfico consiga elaborar seu próprio mapa.

O Google Earth por sua vez, se configura como uma ferramenta valiosa para as práticas pedagógicas de Geografia, onde os professores podem trabalhar com a informação do espaço de vivência dos alunos.(CLAMPTON, 2010) 


\section{A área de estudo}

\subsection{O município de Nova Friburgo}

Nova Friburgo é um município localizado na região serrana do Estado do Rio de Janeiro cujas coordenadas geográficas são de latitude $22 \circ 16$ `55 “ S e de longitude de $42 \circ 31$ `52 “O. Situase a uma altitude de 846 metros ocupando uma área total de 933,41 $\mathrm{km}^{2}$ e com uma população de 182.016 habitantes (IBGE, 2010).

Na região serrana do estado do RJ ocorreu em 2011 a maior catástrofe da história do Brasil, ou megadesastre ${ }^{4}$ sendo que neste município tivemos 0 maior número de óbitos.(BRASIL,ABDN,2012)

Foi verificado que as áreas mais intensamente afetadas pela tragédia foram aquelas consideradas APPs (Áreas de Proteção Permanente), como margens de cursos d'água, encostas com alta declividade e topos de morro ou montanhas.Verificou-se, por outro lado, que nas áreas com a vegetação nativa bem conservada, mesmo quando localizadas em áreas com alta declividade ou topos de morro ou montanha, a quantidade de deslizamentos e rolamento de rochas foi inferior a $10 \%$ do total desses eventos (BRASIL,MMA, 2011).

Neste município, devido às características geológicas com predomínio de relevo de encostas íngremes e escarpadas, solos rasos e clima tropical úmido onde o intemperismo químico e bioquímico é particularmente intenso, o qual fornece sistematicamente materiais terrosos nas encostas passíveis de serem removidos por movimentos de massa (SAUSEN, 2015). Isto ocorre pois tal clima propicia chuvas intensas e frequentes, principalmente no verão,

\footnotetext{
${ }^{4}$ Termo adotado pelo Anuário Brasileiro de Desastres Naturais(BRASIL,ABDN, 2012). Deixando um número incalculável de cicatrizes de escorregamentos em encostas de quatro municípios - Nova Friburgo, Teresópolis, Petrópolis e Sumidouro -, principalmente nas duas primeiras, e provocando prejuízos indiretos por conta de enxurradas em mais três municípios - Areal, São José do Vale do Rio Preto e Bom Jardim. O "Megadesastre" provocou 912 mortes e deixou mais de 45.000 desabrigados e desalojados, caracterizando-se como o maior desastre registrado no Brasil e consolidandoO Megadesastre '11 da Região Serrana do Rio de Janeiro foi um evento catastrófico na história do Brasil. A ocorrência de chuvas intensas em um curto período de tempo, aliado aos altos volumes acumulados no mês antecedente, desencadeou eventos geológicos e hidrológicos em larga escala, que deixaram um enorme rastro de destruição.... o evento pluviométrico durou entre 24 e 32 horas e foi realimentado pela temida Zona de Convergência do Atlântico Sul (ZCAS), gerando tambémtempestades de quatro ou cinco horas (com eventuais pulsos de 15 minutos mais críticos). Ao reunir essas condições atmosféricas favoráveis formando nuvens muito densas, a chuva atingiu patamares realmente extremos, tais como chuvas horárias de $88 \mathrm{~mm} / \mathrm{h}$ a $130 \mathrm{~mm} / \mathrm{h}, 264 \mathrm{~mm}$ em 24 horas e $280 \mathrm{~mm}$ em quatro dias, sucedendo um período de 12 dias com $300 \mathrm{~mm}$ e de um mês antecedente com $619.0 \mathrm{~mm}$. (BRASIL,ABDN, 2012)
} 
associado também às modificações causadas pela intensa ocupação do solo principalmente de maneira desordenada e irregular.

O relatório de Inspeção da tragédia na região serrana do RJ em 2011(BRASIL,MMA,2011) demonstra que se a faixa de 30 metros em cada margem (60 metros no total) considerada Área de Preservação Permanente ao longo dos cursos d'água estivesse livre para a passagem da água, bem como, se as áreas com elevada inclinação e os topos de morros, montes, montanhas e serras estivessem livres da ocupação e intervenções inadequadas, como determina o Código Florestal (BRASIL, 1965), os efeitos da chuva teriam sido significativamente menores.

No mapa a seguir temos a localização do município de Nova Friburgo e das referidas escolas estaduais onde se analisa o grupo de alunos do 10 ano do Ensino Médio nesta pesquisa, ou seja, locais onde foram elaborados os mapas de área de risco com a coleta de dados pelos alunos. Podemos verificar que um dos colégios se localiza no distrito sede (10 distrito-Nova Friburgo), na área urbana (C.E. "A"), e o outro colégio (C.E. "B") localiza-se num distrito mais afastado (no 8o distrito - Mury), com características mais rurais, predominando a cobertura vegetal de floresta.

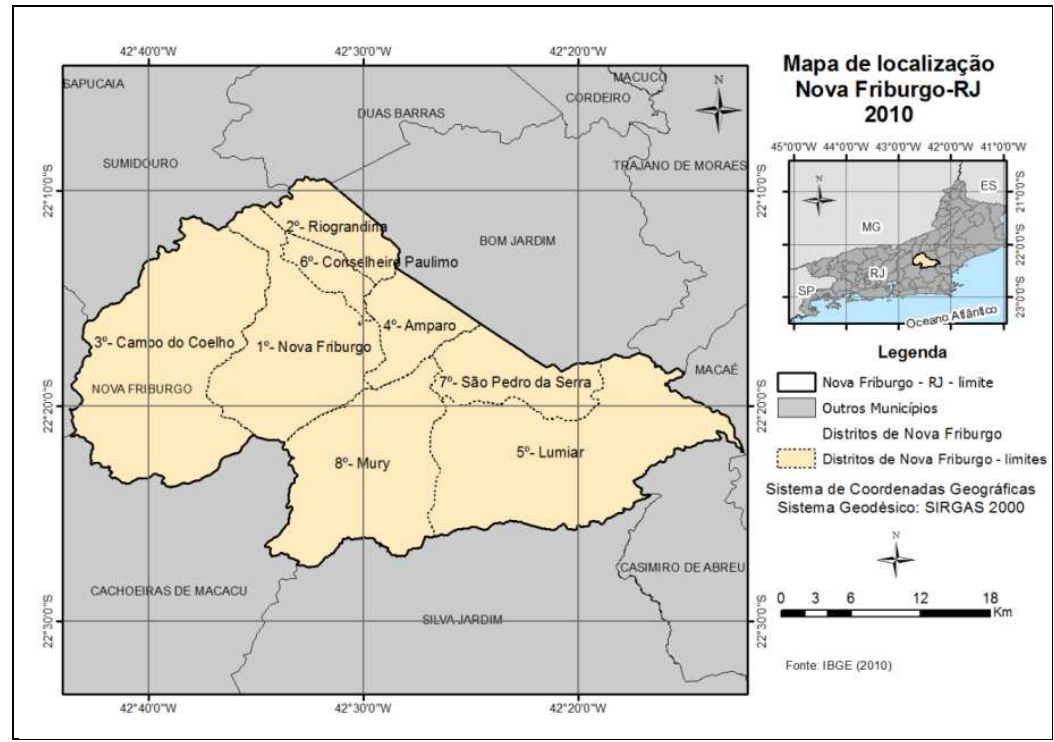

Figura 1. Localização do município de Nova Friburgo-RJ Fonte:O autor (2015). 


\section{Procedimentos metodológicos}

\section{9 etapa:}

Para a pesquisa documental foram obtidos dados dos pontos de risco a escorregamentos e inundações com a Prefeitura Municipal de Nova Friburgo (PMNF-Regea, 2013) onde foram localizadas as maiores ocorrências de escorregamentos e inundações no desastre natural de janeiro de 2011; também foram obtidos dados relevantes para a elaboração dos mapas de vulnerabilidade da população através do site do IBGE (Instituto Brasileiro de Geografia e Estatística): HTTP://www.ibge.gov.br/home. Neste, foi adquirido por download o arquivo Base de Informação do Censo Demográfico 2010: Resultados do Universo por setor censitário.

\section{2a Etapa:}

A presente pesquisa coletou dados de pontos de risco a escorregamentos e inundações em duas turmas do 1 을 ano do Ensino Médio de dois colégios estaduais do município de Nova Friburgo-RJ nos anos letivos de 2014 e 2015.

Para a elaboração deste mapa, foi feita previamente uma explicação em sala de aula da disciplina Geografia, com uso de aparelho multimídia e acesso à internet pelo professor/pesquisador. O intuito era que os alunos pudessem compreender o manuseio do aplicativo Google Earth, gratuito via web. Nas imagens do aplicativo foram inseridos os pontos de risco a escorregamento e inundações percebidos pelos alunos com as ferramentas marcador, linhas ou áreas (com o polígono) disponíveis neste aplicativo. 0 objetivo era adquirir as coordenadas geográficas destes pontos de risco, com as devidas causas inferidas pelos alunos para tal classificação. Ao final, foram no mínimo cinco áreas de risco percebidas pelos grupos de alunos dentro do município de Nova Friburgo-. RJ.

Tais procedimentos foram realizados após a aplicação dos conteúdos da Geografia Física com alunos do 10 ano do Ensino Médio, totalizando 08 turmas (quatro turmas no ano letivo de 2014 e 04 no ano letivo de 2015, com aproximadamente 120 alunos que fizeram o trabalho num total de 240 alunos). Cabe lembrar que a faixa etária destes alunos era entre 15 e 18 anos, tornando possível a elaboração do mapa em computador próprio ou em casas comerciais visto que a sala de informática dos colégios possuía, em média, meia dúzia de 
computadores operantes. Por tais motivos, o trabalho foi dividido em grupos e entregue em formato digital.

\section{3a etapa:}

Com as coordenadas geográficas dos pontos de risco a escorregamento ou à inundação percebidos pelos alunos, elaborou-se uma tabela na planilha eletrônica. Através da ferramenta "join" no software ArcGis 10.0, esta tabela foi convertida no formato "shapefile" relacionando os pontos de risco a escorregamento e inundações no mapa do município de Nova Friburgo com divisão dos distritos, tendo como base os setores censitários.

\section{4a etapa:}

Procedimento análogo ao anterior foi realizado a partir dos dados do mapa de risco a escorregamento e inundações realizado pelos técnicos da prefeitura, os quais e pontuaram os locais que sofreram as maiores ocorrências em janeiro 2011 no município de Nova Friburgo(PMNF-Regea, 2013). As coordenadas foram tabuladas em planilha eletrônica e exportadas para o mapa com divisão dos distritos com imagem do satélite Alos-AVNIR no software Arc Gis 10.0.

\section{5a etapa:}

Os pontos de risco a escorregamento e inundações percebidos pelos alunos foram confrontados, também no formato "shapefile", aos mapas temáticos de renda de salário mínimo por responsável, percentual de responsável alfabetizado, percentual de crianças e idosos do município de Nova Friburgo por setor censitário, para analisar a vulnerabilidade da população através da percepção de risco dos alunos.

\section{Análise dos resultados}

\subsection{Análises dos trabalhos dos alunos no Google Earth}

A coleta dos pontos de risco a escorregamentos e inundações foi feitas através da elaboração pelos alunos, de mapa de risco no final do ano letivo de 2014 e no 3으 bimestre 
de 2015. O exemplo a seguir(figuras 2, 3 e 4) é de uma área de risco identificada por um grupo de alunos da turma 1001 do colégio do distrito sede.

\section{Área de Risco (figuras 2, 3 e 4)}

Na figura 2 temos o uso do marcador para a área de risco em amarelo, com a identificação de coordenadas geográficas em graus, minudos e segundos.

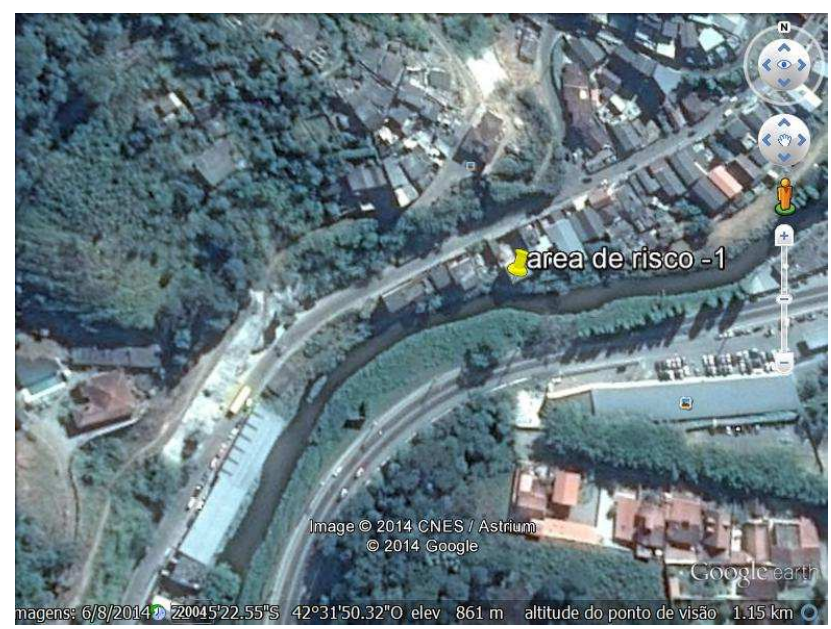

Figura 2-- Área de risco pontuada por um grupo de alunos no Google Earth. Fonte: Grupo de alunos da turma 1001- distrito sede, 2014.

$\mathrm{Na}$ figura 3 temos a mesma área vista pela ferramenta Street view do Google Earth, possibilitando uma aproximação da realidade. Com base nas duas figuras (2 e 3), há a observação do grupo relatada, onde tal área foi considerada como de risco em função de sua localização em relação ao rio principal que corta a cidade.

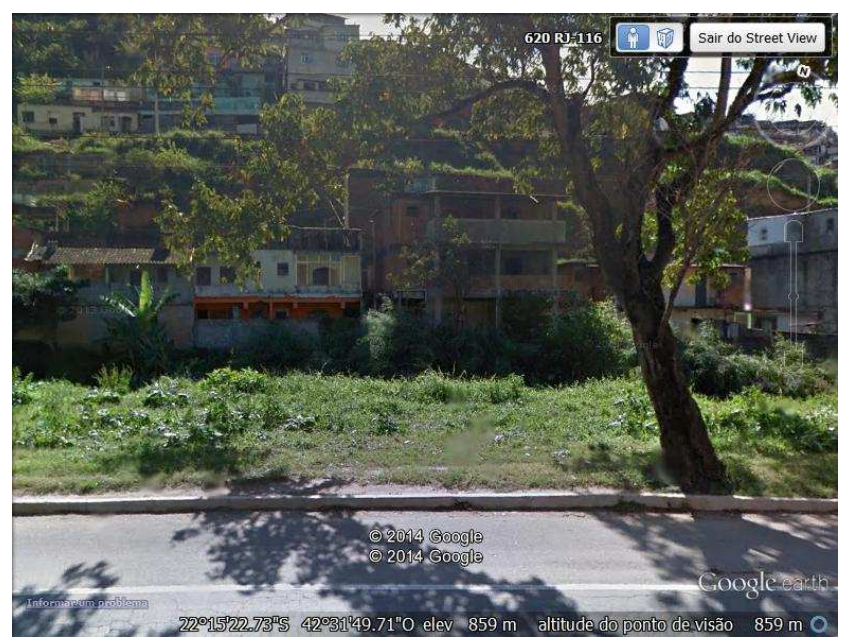

Figura. 3. Utilização da ferramenta Street View Fonte: Gupo de alunos da turma 1001- distrito sede, 2014. 
A observação a seguir foi elaborada por este grupo de alunos:

"Área de Risco 1- localizada em Duas Pedras, as residências têm grande proximidade ao Rio Bengalas. Ao chover, há grande probabilidade das casas se alagarem e até desmoronarem". A figura 4 fornece outro exemplo de uma área de risco pontuada por um grupo de alunos com a ferramenta Street View do Google Earthe captação das coordenadas geográficas que se encontram na parte inferior da figura.

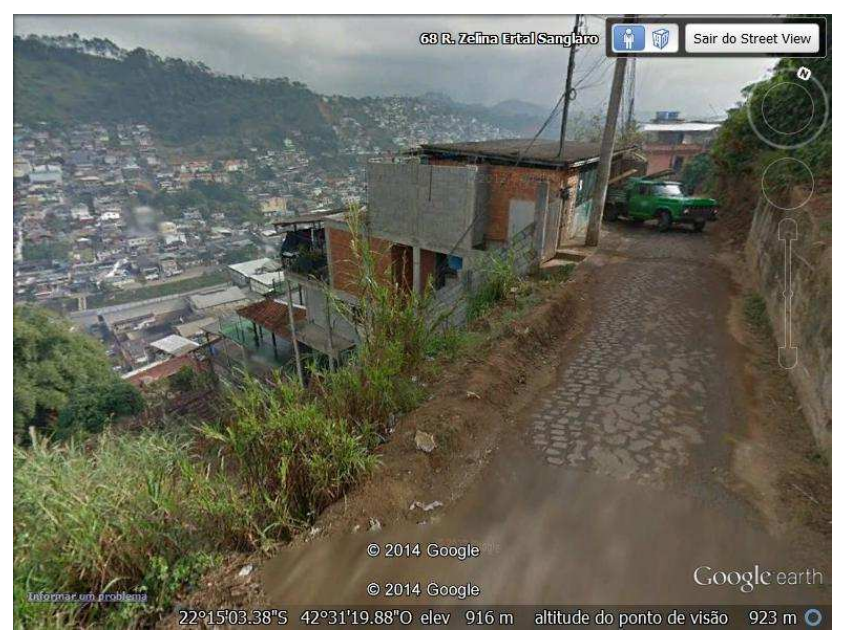

Figura. 4- Área de risco com a utilização da ferramenta do Street View do Google Earth em um dos trabalhos de um grupo de alunos.

Fonte: Grupo de alunos da turma 1001- distito sede, 2014.

Para a figura 4, houve a seguinte observação feita pelos alunos da precariedade das construções numa área de declividade acentuada:

Área de Risco 3- Localizada na rua Zelina Erthal na comunidade do Rui Sanglard, pode-se ver pelo menos 5 residências amontoadas, em uma área de grande declividade".

\subsection{Análise do mapa de risco a escorregamento e inundação com pontos da prefeitura}

$\mathrm{Na}$ figura 5 estão mapeados os pontos de risco a escorregamento e inundações com as coordenadas geográficas adquiridos junto a Prefeitura Muncipal de Nova Friburgo (PMNFRegea, 2013). Os pontos em vermelho são os escorregamentos e em azul, que foram poucos (três casos), são as inundações. 


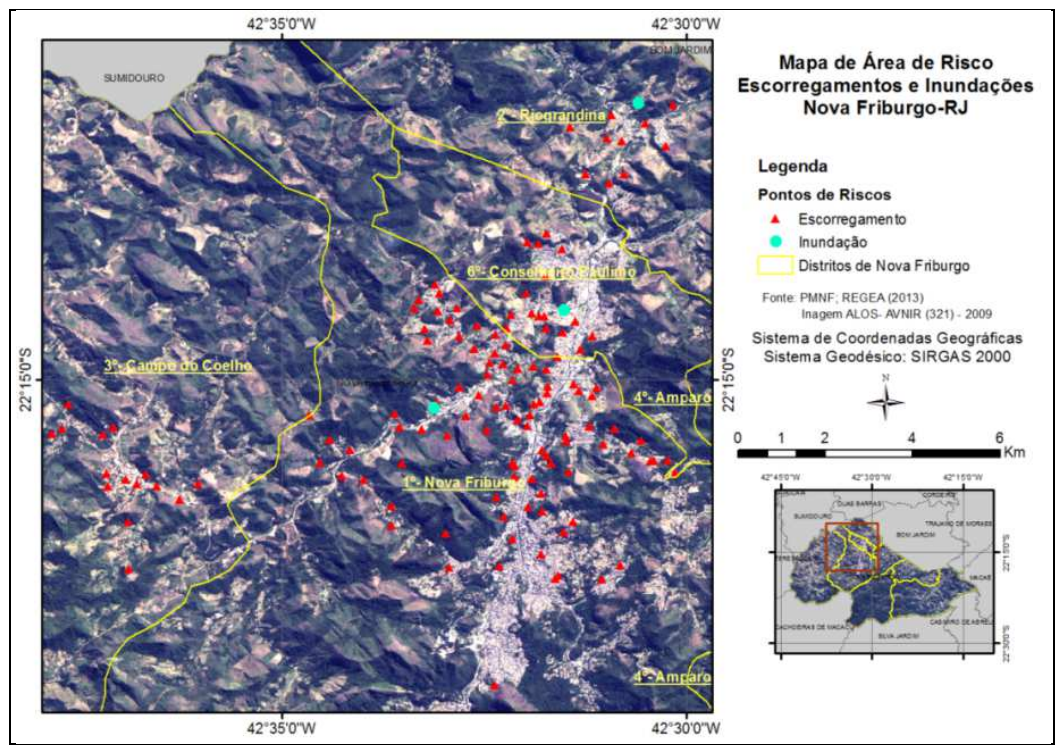

Figura 5- Mapa de risco a escorregamento e inundações com pontos adquiridos pela PMNF-Regea, 2013.

Fonte: $O$ autor (2015).

\subsection{Análise dos mapas temáticos}

Os mapas temáticos a seguir foram elaborados a partir dos dados do IBGE, com a alocação dos pontos de risco a escorregamento e inundações percebidos pelos alunos das duas escolas. Estes pontos coincidiram muito entre elas e coincidiram com os pontos da prefeitura, visto que a maioria dos pontos de risco se concentraram no distrito sede e com alguns casos, próximos aos colégios dos alunos, destacando a vivência dos mesmos, a memória dos locais das ocorrências de 2011 ou mesmo devido a relatos da comunidade e influência da mídia. No detalhe, podemos observar que a maioria dos pontos de risco a escorregamento e inundações se encontram no distrito sede.Merece destaque o fato de os pontos de risco a escorregamento e inundações identificados pelos alunos foram em maior quantidade do que os pontos oficiais.

\subsubsection{Mapa renda por responsável em salários mínimos}

Na figura 6 está o mapa de rendimento da renda por responsável em salários mínimos por setor censitário tendo como base o Censo do IBGE (2010). Os alunos consideraram os pontos de risco a escorregamentos e inundações pós desastre de 2011 não somente nas áreas de menor rendimento de salário, demonstrando que tais acontecimentos atingem 
todas as classes e principalmente a classe intermediária (1,9 a 5,5 salários mínimos) na área mais urbanizada do município. Para Nova Friburgo então, a percepção pós evento de 2011 não foi a classe de menor rendimento a que possui maior vulnerabilidade ao desastre natural.

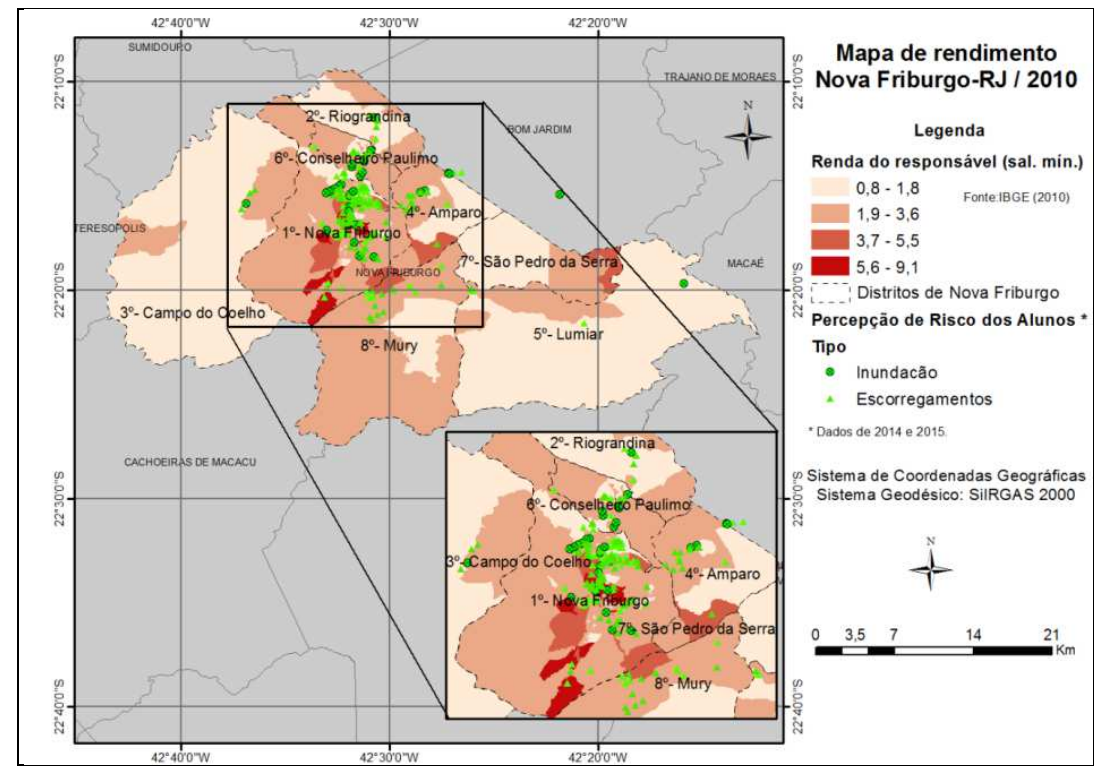

Figura 6. Mapa de rendimento de Nova Friburgo por responsável renda e vulnerabilidade por renda da população percebidos pelos alunos (2014 e 2015).

Fonte: 0 autor(2015)

\subsubsection{Mapa de percentual de pessoas alfabetizadas:}

A figura 7 mostra os pontos de risco a escorregamento e inundações percebidos pelos alunos por setor censitário em relação ao percentual de pessoa alfabetizadas. Na área ampliada, podemos observar que a população mais alfabetizada foi a mais atingida pelos escorregamentos e inundações no município de Nova Friburgo. Esta percepçãodos alunos difere de muitos estudos, como a base conceitual desta pesquisa, que classifica como a população menos alfabetizadacomo a mais vulnerável. 


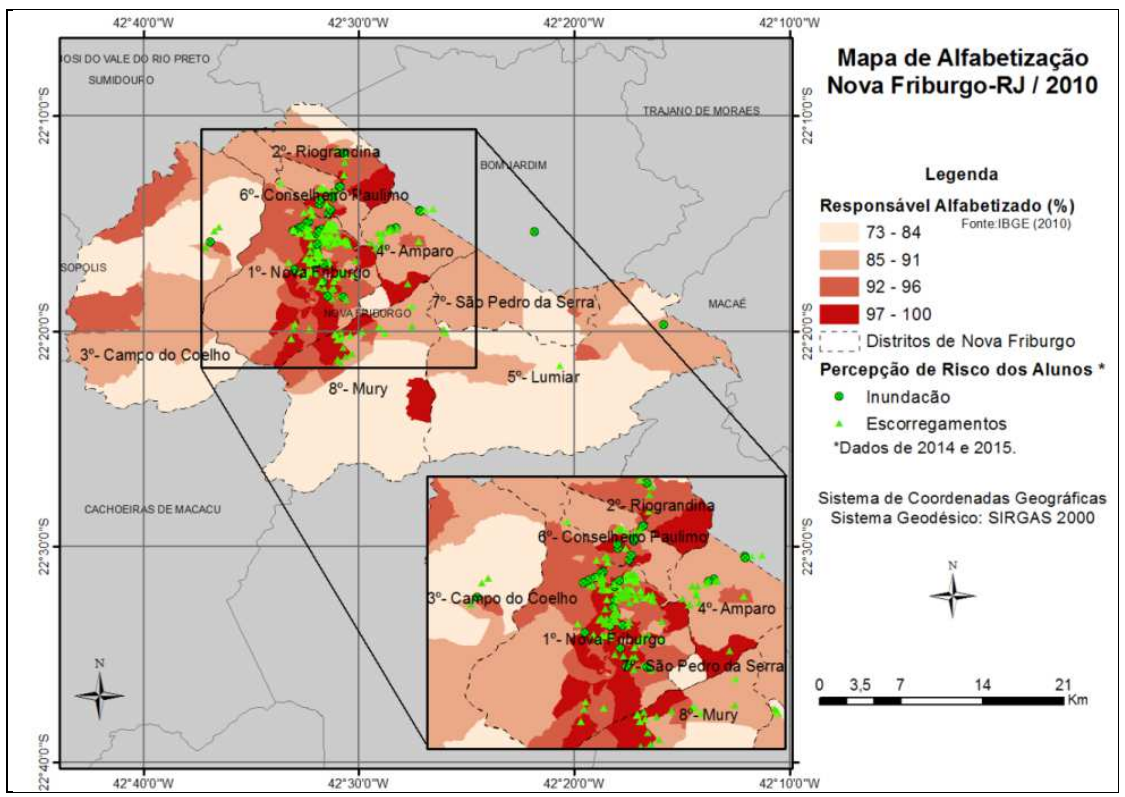

Figura 7- Mapa de percentual de pessoas alfabetizadas no município de Nova Friburgo vulneráveis a escorregamento e inundações percebidos pelos alunos (2014 e 2015).

Fonte: $\mathrm{O}$ autor (2015).

\subsubsection{Mapa de percentual de crianças}

Na sequência, encontra-se a figura 8, com o mapeamento do percentual de crianças, habitantes mais vulneráveis a escorregamento e inundações; o percentual é de pequeno a médio, como podemos observar na ampliação da figura 8.

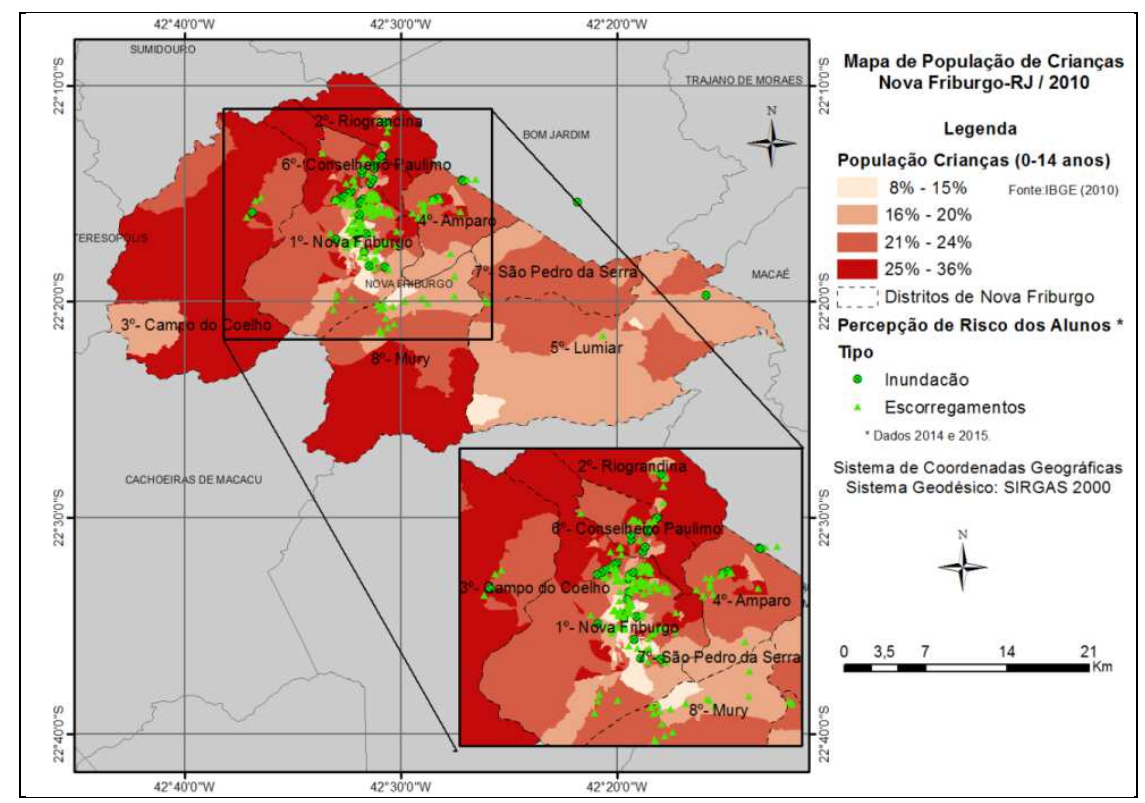

Figura 8- Mapa de percentual de crianças por setor censitário de Nova Friburgo vulneráveis ao risco de escorregamento e inundações percebido pelos alunos (2014 e 2015).

Fonte: $\mathrm{O}$ autor (2015). 


\subsubsection{Mapa de percentual de idosos}

Finalizando a análise dos resultados junto à vulnerabilidade da população frente ao risco de escorregamento e inundação percebidos pelos alunos por setor censitário do IBGE (Censo, 2010) temos a figura 9. Nesta, podemos observar que o percentual de idosos das áreas mais suscetíveis a escorregamento e inundações é de médio a grande.

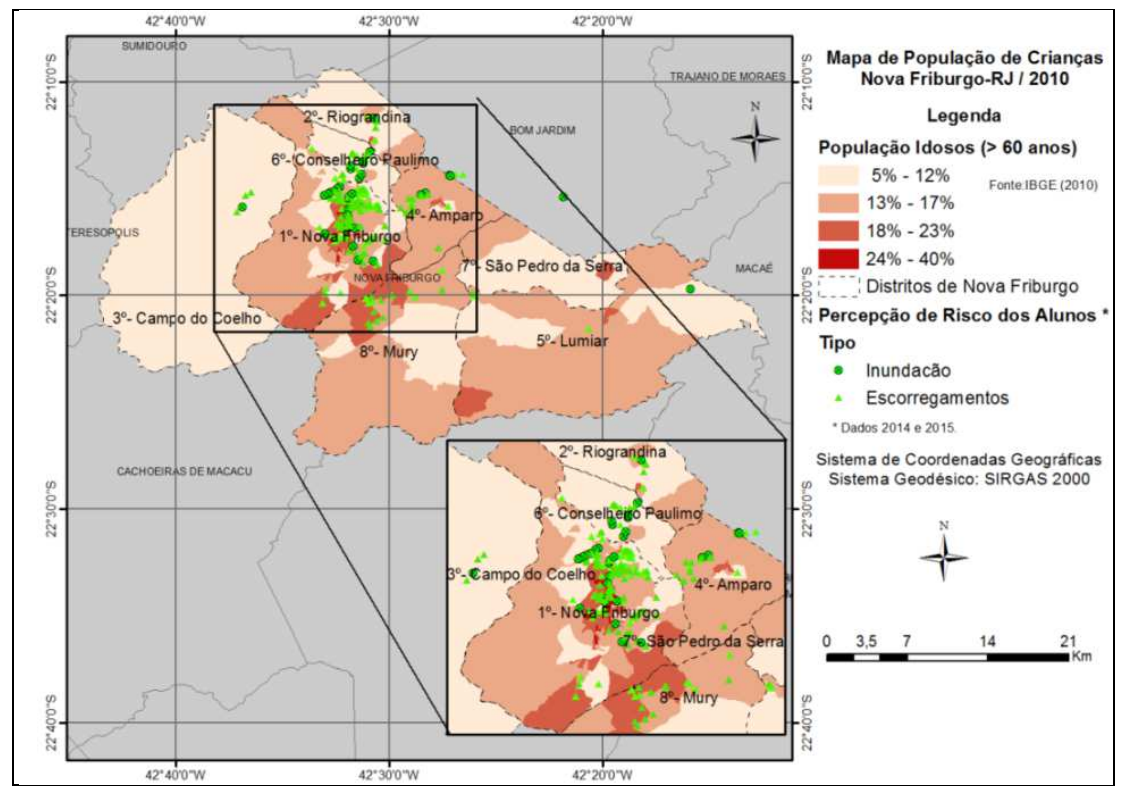

Figura 9- Mapa de percentual de idosos vulneráveis ao risco de escorregamento e inundações percebidos pelos alunos (2014 e 2015).

Fonte: O autor (2015)

\section{Considerações finais}

O presente trabalho baseia-se no conceito de percepção de risco através da análise da mesma pelos alunos do 10 ano do Ensino Médio em duas escolas da rede estadual do Rio de Janeiro durante os anos letivos de 2014 e 2015 no município de Nova Friburgo-RJ após o desastre natural em janeiro de 2011.

Nesta análise, um dos procedimentos foi a utilização, como ferramenta pedagógica, o uso do aplicativo Google Earth gratuito via internet finalizando com a elaboração de mapas de área de risco pelos alunos. Com este aplicativo, os alunos puderam se aproximar da 
realidade em que vivem através do manuseio das imagens de satélites assim como obtiveram a introdução das geotecnologias que vem de acordo com os PCN para a disciplina geografia para o referido ano, atuando como apoio pedagógico e motivacional para as aulas de Geografia. Ao mesmo tempo, podemos observar a viabilidade de uma medida de prevenção a risco de escorregamentos e inundações que muito ocorrem neste município.

Com a disciplina Geografia podemos auxiliar no mapeamento de áreas de risco, o que foi possível junto aos alunos com o uso do aplicativo Google Earth

O mapa de área de risco fornece condições de cobrança pela população junto aos nossos gestores públicos para uma melhor gestão dos riscos e planejamento territorial visto que o embasamento para a elaboração dos mesmos coincidiu com o desrespeito as APPs (Área de Proteção Permanente) como exposto no Relatório de Inspeção do Ministério do Meio Ambiente.(BRASIL, MMA, 2011)

Com este trabalho elabora-se também uma Educação Ambiental quando pensamos em proteção as bacias hidrográficas. Ademais, até o momento, a disciplina defesa civil não foi inserida na grade curricular do Ensino Básico, mas vem ao encontro dos Parâmetros Curriculares Nacionais para a disciplina Geografia o que abre um leque de oportunidades para inserir a prevenção ao risco ao desastre nesta disciplina.

Através da análise dos mapas da divisão do município por setores censitários observaram-se algumas quebras de paradigmas para o desastre natural ocorrido em janeiro de 2011 no município de Nova Friburgo. Neste município, a população de baixa renda, baixa escolaridade e crianças não foram os mais afetados pelos desastres naturais deste grande evento. Dentre as variáveis de vulnerabilidade social e econômica geralmente mais vulneráveis a escorregamentos e inundações como as citadas, todas são consideradas mais vulneráveis. Entretanto, o que foi verificado nesta pesquisa através dos mapas dos pontos de risco percebidos pelos alunos dos dois colégios estaduais, é que a maioria dos pontos de risco a escorregamentos e inundações ocorreu no distrito sede, que é a área central do município e onde se concentra a população mais idosa, a de renda salarial média para alta e a população mais alfabetizada, demonstrando quebras de paradigmas. 
Com estes resultados podemos observar que a percepção de risco dos alunos através da vivência pós um grande desastre natural demonstra que toda a sociedade está envolvida sem grande distinção de classes e condição social. Tais resultados coincidiram muito nas duas escolas envolvidas mesmo de espacialidades diferentes (uma mais urbana e outra mais rural). Entretanto, observamos poucas particularidades visto que alguns pontos de risco ficaram próximos aos diferentes colégios. Assim, medidas de prevenção e mitigação de desastres são urgentes e devem atingir toda a sociedade e a elaboração e compreensão do mapa de área de risco pelo público leigo fornece condições para o melhor planejamento territorial onde o aplicativo Google Earth pode nos inserir diante da introdução das geotecnologias que é uma ferramenta importante para mapeamento de área de risco. Espera-se com esta pesquisa que este procedimento pode ser seguido também em outras turmas de 1음 ano do Ensino Médio em diferentes escolas numa expectativa de se aprimorar a percepção de risco dos alunos que podem ser multiplicadores de informação para suas comunidades.

\section{Referências}

BRASIL. Lei n 4.771, de 15 de Setembro de 1965. Institui o código florestal. Diário oficial da União, 1965.

BRASIL. (IPT)Mapeamento de Riscos em Encostas e Margem de Rios. Brasilia, 2007.176 p. Disponivel em:<http://www.cidades.gov.br/images/stories/ArquivosSNPU/Biblioteca/PrevencaoErradicacao/Livro Mape amento Enconstas Margens.pdf>. Acesso em: 23 ago. 2013.

BRASIL. Lei no 12.608, de 10 de abril de 2012. Institui a Política Nacional de Proteção e Defesa Civil - PNPDEC; dispõe sobre o Sistema Nacional de Proteção e Defesa Civil - SINPDEC e o Conselho Nacional de Proteção e Defesa Civil - CONPDEC; autoriza a criação de sistema de informações e monitoramento de desastres; altera as Leis no 12.340, de 10 de dezembro de 2010, 10.257, de 10 de julho de 2001, 6.766, de 19 de dezembro de 1979, 8.239, de 4 de outubro de 1991, e 9.394, de 20 de dezembro de 1996; e dá outras providências. 2012 a. Disponível em: http://www.planalto.gov.br/ccivil_03/_Ato2011- 2014/2012/Lei/L12608.htm. Acesso em: 15 jun.2014.

BRASIL. Lei no 10.257, de 10 de julho de 2001. Regulamenta os arts. 182 e 183 da Constituição Federal, estabelece diretrizes gerais da política urbana e dá outras providências. Disponível em: http://www.planalto.gov.br/ccivil_03/leis/leis_2001//10257.htm. Acesso em: 13 jan. 2012.

BRASIL. Secretaria de Biodiversidade e Florestas. Relatório de Inspeção Área atingida pela tragédia das chuvas Região Serrana do Rio de Janeiro: Áreas de Preservação Permanente e Unidades de Conservação \& Áreas de Risco $O$ que uma coisa tem a ver com a outra? Brasília, 2011. Disponível em: <http://www.mma.gov.br/estruturas/182/ arquivos/relatoriotragediari 182.pdf. $>$ Acesso em: 05 maio 2015.

BRASIL. Secretaria de Biodiversidade e Florestas. Atlas Brasileiro de Desastres Naturais 1990 a 2001. Volume Rio de Janeiro. Florianópolis: CEPED/UFSC, 2012.Disponível em: <http://150.162.127.14:8080/volumes/volumes.html > Acesso em: 12 nov. 2014. 
BRASIL. Secretaria Nacional de Defesa Civil. Centro Nacional de Gerenciamento de Riscos e Desastres. Anuário brasileiro de desastres naturais: 2012. Brasília: CENAD, 2014. 84 p. Disponível em: http://www.integracao.gov.br/c/document library/get file?uuid=f22ccccd-281a-4b72-84b36654002cff1e6\&groupld=185960. Acesso em: 07 jul. 2014.

BRASIL. Parâmetros Curriculares Nacionais.Secretaria de Educação Fundamental. Terceiro e Quarto Ciclos, G, Geografia. Ministério da Educação.Brasília. 1998.

BRASI. Política Nacional de Defesa Civil.Brasília. Diário Oficial da União. 2007.

BRÜGgEMAN, Fábio. Percepção de risco: a descoberta de um novo olhar: livro do professor. Florianópolis: Defesa civil de Santa Catarina. 2009.

CARVALHO, V. M. S. G. Sensoriamento Remoto no ensino básico da geografia: definindo novas estratégias. 2006. Tese (Doutorado em Geografia) - Instituto de Geociências, Universidade Federal do Rio de Janeiro, Rio de Janeiro, 2006.

CASTRO, Antonio Luiz Coimbra. Glossário de defesa civil estudos de riscos e medicina de desastres. 2.ed.rev. ampl. Brasília: Secretaria Nacional de Defesa Civil, $1998 . \quad$ Disponível em:<http://www.defesacivil.mg.gov.br/conteudo/arquivos/manuais/Manuais-de-Defesa-Civil/GLOSSARIODicionario-Defesa-Civil.pdf>. Acesso em: 05 juL. 2015.

CATANHO, Pedro Ananias Gomes. A gestão do risco de desastres começa na escola: desenvolvendo a percepção de risco através da educação. 2012. Monografia (Especialização) - Faculdade Metropolitana da Grande Fortaleza. 2012. Disponível em: <www.defesacivil.ce.gov.br/index.php?option=com...id...>Acesso em: 20 ago. 2015

CLAMPTON, J. W. Map 2.0 map mashups and new spatial media . In: Mapping: A Critical Introduction to Cartography and GIS. London: John Wiley, 2010. p. 13-24.

COELHO NETO, A.L.Hidrologia de encosta na interface com a geomorfologia. In: GUERRA; A.J.T; CUNHA. S. B da (Org.). Geomorfologia: uma atualização de bases e conceitos. Rio de Janeiro: Bertrand, 1995. P.93-148.

GIL, A.C. Métodos e técnicas de pesquisa social. 6 ed. 6 reimpr. São Paulo. Atlas. 2014.p.8-18 e 121-124.

HOGAN, D. J. et al. Urbanização e vulnerabilidade sócio-ambiental: o caso de Campinas. Campinas: EdUNICAMP, 1992. Disponível em: <www.nepo.unicamp.br/.../02pronex 13 Urbanizacao...>. Acesso em: 10 abr. 2014.

IBGE. Cidades. 2010. Disponivel em: <http://www.ibge.gov.br/cidadesat/topwindow.htm?1>. Acesso em: 03 fev. 2012.

MARANDOLA; MODESTO, F. Percepção dos perigos ambientais urbanos e os efeitos de lugar na relação população-ambiente. R. bras. Est. Pop., Rio de Janeiro, v. 29, n. 1, p. 7-35, jan./jun. 2012. Disponível em: <http: www.scielo.br/pdf/rbepop/v29n1/v29n1a02.pdf>. Acesso em: 22 mai 2014.

MARCELINO, E. V. Desastres Naturais e Geotecnologias: conceitos básicos. Santa Maria : INPE, 2008. Disponível em http://www.inpe.br/crs/geodesastres/imagens/publicacoes/conceitosbasicos.pdf. Acesso em 10 ago. 2011.

NAÇÕES UNIDAS. Living with risk: A global review of disaster reduction initiatives. Genebra: UN, 2004. 457p. Disponível em: <http://www.unisdr.org/we/inform/publications/657>. Acesso em: 03 jan. 2015.

NAÇÕES UNIDAS. Terminología sobre Reducción del Riesgo de Desastres.USA, 2009.

NOVA FRIBURGO. Programa "Apoio à prevenção e erradicação de riscos em assentamentos precários". Plano Municipal de redução de riscos. Regea. Relatório da etapa 2. Elaboração da revisão do plano municipal de redução de riscos. 2013.

SAUSEN, T. M. Desastre Zero-Mapa de risco em sala de aula com o auxílio do Google Earth. In: Simpósio de Sensoriamento Remoto, 16., 2013, Foz do Iguaçu. Anais XVI Simpósio de Sensoriamento Remoto. Disponível em: <http://marte2.sid.inpe.br/rep/dpi.inpe.br/marte2/2013/05.28.22.47.51>. Acesso em: 20 jul. 2014. 
SAUSEN, T. M.; LACRUZ, M. S. P. (Org.) Sensoriamento Remoto para Desastres. São Paulo. Oficina de Textos. 2015.

TOMINAGA, L. K.; SANTORO, J.; AMARAL, R. (Orgs.).Desastres naturais: conhecer para prevenir. São Paulo : Instituto Geológico, 2009.

TUAN, Yi-Fu. Espaço e Lugar: a perspectiva da experiência. São Paulo:DIFEL, 1983.

VEYRET, I. Riscos: O homem como agressor e vítima do meio ambiente. São Paulo: Contexto, 2007. 